\title{
The Effect of Classroom Environment on Achievement in English as a Foreign Language (EFL): A Case Study of Secondary School Students in Gezira State: Sudan
}

\author{
Abdul-Majeed Attayib Umar, ${ }^{1, *}$ \\ ${ }^{1}$ Department of English, University of Khartoum, Khartoum, Sudan \\ *Correspondence: Department of English, University of Khartoum, Khartoum, Sudan. E-mail: \\ drtayib@hotmail.com
}

Received: December 1, 2017

Accepted: December 10, 2017 Online Published: December 17, 2017

doi:10.5430/wjel.v7n4p1

URL: https://doi.org/10.5430/wjel.v7n4p1

\begin{abstract}
Classroom environment plays a significant role in determining students' level of academic achievement and enhancing their holistic growth. For students, the classroom is not just an intellectual space, but also a social, emotional and physical environment. The purpose of this study is to examine the effects of classroom environment on learning English as a foreign language by a group of first grade students at Secondary Schools in Gezira State in the Sudan. This study indorses the experimental approach to realize its objective. Two groups of students are classified as the Experimental and the Control group and assigned to study under two different classroom environments. The Experimental group consists of (122) students. These are accommodated in three well renovated classrooms; while the Control group which includes (135) students are assigned to study in non-renovated schools under relatively poor classroom environments. The two groups are taught the same English language material by teachers with similar qualifications and experiences during the first term of the academic year 2016. Scores in the English Final Examination for the two groups are compared to check the classroom environment effect on the students' achievement. These scores are tabulated and analysed using descriptive statistics. The results reveal that there are significant differences between the achievements of the Experimental and the Control group in English in favour of the Experimental group who have studied under favourable classroom conditions. The researcher has also explored the administrators' and teachers' viewpoints regarding the learning environment in the study zone and its possible impact on students' achievement in English. The study ends up with some recommendations including conducting further studies on the environmental effect on other school subjects and on female students' achievement.
\end{abstract}

Keywords: classroom environment; physical elements; learning resources; academic achievement

\section{Introduction}

The classroom is the place where the students learn the various skills that are necessary to qualify them to become significant adults. Ashton (2001) states that a classroom is where the students gain understanding of the contribution that they can make to build their identity and their society. It is where the students acquire the knowledge needed to achieve their ultimate goals and objectives in future life.

With the classroom being such an important place in the growth and development of a student, it is important, therefore, to understand the ways in which to form its environment in order to have maximum effective instruction. If schools play a major role in teaching the students how to be successful adults, then every necessary measure should be taken to safeguard that the learning environment is one that helps students work hard to achieve success. If not dealt with adequately, a classroom can be set up in a way that hinders creativity or, at least, in a way that does not promote acceptable learning level (Kilie, 2012). There are many things that can affect this environment. These may include physical elements such as wall art, arrangement of desks, and other learning resources. Also, there are non-physical elements such as the classroom regulations and rules, or even the sounds and light within the room. Each of these can affect a student's focus and hence his learning in the class. These elements can also affect the 
teacher's attitude in the class as well (Dihaisat, 2016). Additionally, the way in which a teacher controls the class, or manages it, will have positive or negative influence on the students (Best \& Kahn, 2001).

The standard for many classrooms in the past was to have a blackboard and a set of desks arranged in rows within the classroom. This system of arrangement may not fit students in today's schools. Some modern educators claim that such traditional arrangements make students lose interest and create a higher level of boredom in the classroom (Umar, 2015). Rogers \&George suggest that this structure does not encourage interaction between students which represents a crucial element, particularly, in language learning.

Most researchers agree that the physical environment of the classroom makes a noticeable impact on students' achievement. This can have a variety of details. It can be the structure of the classroom, the ventilation, the classroom size, the learning resources, or even the colours of the classroom walls and decoration or pictures. All of these can play a role in determining whether the classroom will be conducive for learning. However, each of these elements alone may not have a large effect, yet together they can work to strengthen a student's ability to learn. .

In the case of language learning, adding various language labs makes the students feel that this is a classroom that requires active involvement in its activities. It also reflects that the students will not just sit and take notes, but they will act out as active members in that classroom. A classroom environment that allows students to work together in order to perform their learning tasks and allows maximum cooperative learning will represent an ideal classroom environment which in its turn pave the way for a successful and joyful language learning experience (Tayib, 2015)

Tsavga (2011) asserts that the learning environment plays a crucial role in determining students' success as it determines how a student behaves and handles his learning tasks. Indeed, the environment in which one finds himself tends to mould his behaviour so as to meet the demands of learning.

In the Sudan, where this study takes place, the researcher observes that the desire for providing quality education has increased and thus multiplies the responsibility for establishing a classroom environment that is effective and conducive to learning. It is generally known that poor classroom environment is expected to reflect negatively on students' performance.

\subsection{Statement of the Problem}

The negative influence of inadequate classroom environment on academic achievement of students in general and on foreign language learning in particular has been an issue of concern to all partners in the educational arena. More specifically, it is reported that secondary schools students' performance in English and in entrance examinations in Sudan is low and not satisfactory. Many educators in the area have attributed this to poor classroom environment. In this regard, the researcher confirms that, with exception of a few newly renovated schools, most classroom environments in the study area have not been suitable for teaching and learning and indeed this is bound to have a serious impact on students' achievement in English; a case which needs careful assessment and in-depth investigation.

\subsection{Purpose of the Study}

The main purpose of this study is to investigate the influence of classroom environment on the performance of the first grade Secondary School students in English in Gezira State of the Sudan. Specifically, this study seeks to assess the influence of classroom physical environment on achievement of first year secondary school students in English and to give some practical suggestions to promote the learning environment.

\subsection{Research Questions}

The following research questions are formulated to direct the study:

1. What is the influence of classroom environment on the achievement of first grade secondary schools students in English in Gezira State in Sudan?

2. What elements in the classroom environment which influence language learning most?

3. What do stakeholders need to do to improve classroom environment to make it more conducive to learning English in a Sudanese setting?

\subsection{Research Hypothesis}

HO. Provision of adequate Classroom facilities will have a positive influence on the achievement of Sudanese secondary school students in English. 


\subsection{Significance of the Study}

This study is significant because its findings will draw parents', school managers', teachers', students' and the society's attention to the importance of creating an adequate learning environment in classrooms. Consequently, the findings of this study will assist school administrators and curriculum designers to develop strategies that promote classroom atmosphere and make it more suitable for learning English in Sudanese secondary schools. Furthermore, the findings of the study will act as a reference to other fellow-searchers interested in this area of study.

\section{Literature Review}

\subsection{A Theoretical Background and Previous Studies}

Ashton (2001) reports that environment is a place where the child grows up to function as a positive member in the society. It includes the home, the school, the peer group, and the classroom. It covers all that is related to the child's upbringing including his /her spiritual life, social requirements, and psychological needs.

At the level of education, Nwangwu (1990) numerates the various elements that constitute the school environment. For him these include school buildings, classrooms, furniture, playgrounds, sporting facilities, laboratories, libraries and the other equipment which aid the teachers in delivering effective lessons.

\subsection{School Environment and Teaching-Learning Process}

The school environment is an essential part of educational planning. The quality of education does not only depend on the teachers as shown in the performance of their duties, but also in the effective coordination of the school environment,(Chuma 2012).It is believed that a well-designed school environment will help to achieve the expected outcomes of education through effective teaching and learning process. Effective teaching is likely to yield outstanding students' performance. Kilel (2012) assures that provision of sufficient learning facilities, and instructional materials, within suitable classroom atmosphere and proper school location are some factors in the school environment that are found to have an impact on the teaching-learning process. This may lead to the conclusion that the school environment would remain as an important issue that should be studied and well managed to secure reasonable students' academic achievement.

\subsection{Impact of School Facilities on Students' Achievement}

Physical facilities in terms of adequacy and quality have been noted to have great impact on performance of students in examinations. Heyneman and Loxley (1993) in their research on the effect of availability of physical facilities on academic performance find out that the presence of school library and audio-visual aids relate strongly to achievement in Brazil, China, Botswana and Uganda. He assures that the library is an important element in the teaching-learning process. A library is classified as an instructional resource which may significantly influence the teaching-learning process and eventually the performance of students (Fuller, 1986).

Umar (2015) reports that school environment manifested in classrooms design, desks' arrangement and books availability strongly correlate with good performance in English among students in the Arab countries.

Researchers in the same field report that crowded classroom conditions make it difficult for learners to concentrate, and consequently minimize the time teachers can utilize in actual teaching of students. Chuma $(2012)$ notes that congestion within classrooms hinders the teaching-learning process. He explains that this happens because the teacher may not be able move around to give individual directions to all due to the large number of pupils in class.

It is generally documented that schools with adequate facilities stand a better chance of providing quality education. In this regard, Hines (1996) reports that students' achievement is as much as 11 percentile points higher in standard buildings, as compared to their performance in substandard buildings.

\subsection{Adequacy of Teaching Materials and Textbooks}

Availability of adequate teaching materials is a key element in a successful implementation of any syllabus. Collin and Rosmiller (1987) assure that even highly qualified teachers would fail to teach effectively without adequate facilities or if they are lacking the necessary teaching aids. Ashton (2001) observes that instructional resources are essential in planning and implementing a successful learning program. He adds that availability of learning aids is the most influential factor which explains various performance levels and concludes that the use of proper instructional materials leads to better performance.

Quite recently, Hassan (2016) finds a strong relationship between adequate provision of well-designed textbooks, teaching aids and achievement. Textbooks, he says, are often the most cost effective means for improving academic 
achievement and increasing the efficiency of students. A few years earlier, Salem, (2003) stresses the importance of having enough textbooks for all students, adding that textbook-ratio should be one- to- one in all school levels. Sharing of these books may have a negative effect on the students' level of concentration.

\subsection{Class size and the Teaching-Learning Process}

Classroom size has a great impact on the teaching-learning process. The more reasonable the class size, the easier it is for teacher-learner interaction which stands as an essential element in the process of language teaching. Generally, teachers are fully aware of the importance of direct interaction for language learning. Hence, a large class size may have a negative impact on the teaching-learning process since the teacher cannot provide feedback for a large number of students or he may not have enough time to assess their work as they are doing their exercises.

According to the National Council for Teacher Education (NCTE) in India, small class size leads to proper engagement of the learners, increases their participation and attentiveness, and keeps them alert. Smaller class size allows educators to focus more on the pupils in their teaching and results in better understanding and helps the teachers to adjust their methods to meet individual students' needs. At another level, it is found that large class size makes monitoring of students' very difficult and thus encourages pupils' disruptive behaviour (Bascia, 2003). Furthermore, the quality of feedback to students, says Bascia, becomes very low and slow in classes with large number of students.

The studies reviewed above reveal that classroom environment does have a significant influence on students' level of performance. Classroom environment enhanced with accessibility of adequate teaching materials and other facilities is bound to secure students' success in learning different subjects including language. Indeed, positive environment coupled with good quality instructional materials can motivate interest, maintain concentration and make learning in general and language learning in particular a more enjoyable, meaningful and fruitful experience.

\section{Research Methodology}

In this part, the researcher explains the methodology and the procedure used in the study and describes each step separately. The researcher describes the setting, the sample of the study, the tools, the data collection and the data analysis procedures.

\subsection{The Setting}

This study is conducted in Gezira State within the Municipality of Greater Wadmadani in the Sudan. The population of the study covers all the seventeen public secondary schools for boys in the region. Eight of the schools in the Municipality have undergone radical renovation and some of them are even completely knocked down and rebuilt according to the standard set by the Ministry of Education for school buildings. This is done as part of the Reform Program indorsed by Gezira State in Sudan. The rest of the schools in the Municipality remain in their relatively poor conditions waiting for their turn to be renovated in the future. The study is carried out on a sample of students from three renovated and three non-renovated secondary schools during the first term of the academic year 2016-17. The first term normally starts in July and ends in October. Students study their normal English language syllabus entitled (The Spine Course for the Sudan) under two different classroom environments.

\subsection{The Sample and Sampling Procedure}

Stratified sampling technique is used to select the sample for this study from a total population of about 1000 subjects of first year students. Accordingly, the population above is classified into two categories representing those who study their English course under relatively poor classroom environment and those who study the same course under fairly favourable classroom environment. From these two distinguished categories two groups are selected to represent the sample of the study. The selected sample is formed the Control group which includes 135 students studying in three classes under relatively poor learning environment, and the Experimental group students who study in the newly renovated schools. The Experimental group includes 122 students studying in three well designed and renovated classes. The level of achievement of the Experimental and the Control group who study under different classroom environments is obtained through an achievement test given at the end of the term to both groups.

\subsection{Research Tools}

This experimental study is intended to collect required data through a variety of tools. However, the necessary information is initially obtained through close observations of classroom environment. Furthermore, information is gathered through interviews and conversations with the schools' teachers and administrators, and finally but most importantly, through students' scores in English in an achievement test designed and validated by a group of English 
language experts. The scores of the students in the Experimental and those in the Control group in the achievement test will be compared to check the effect of classroom environment on the level of students' achievement in English.

\subsection{Procedure}

Before the study begins, the researcher has arranged several visits to the study area which includes both the renovated and the non-renovated schools and observes the classrooms very closely to record all aspects of the classrooms' environment. These aspects cover the seats organization, the classroom ventilation, room temperature, size of the classroom, the learning resources and teaching aids, level of cleanliness, and the type of furniture the student's use. The information and data obtained have clearly confirmed that the environments of the classrooms of the renovated and non-renovated schools are quite different. Renovated schools, from which the Experimental group is purposively selected, have more favourable classroom environment compared to classrooms earmarked for the Control group.

The researcher has also met with and interviewed the target schools administrators and the English language teachers to inform them about the research and its objectives and also to obtain their consent and their support for conducting the study. During these interviews, the administrators and teachers have provided some valuable advice and information relevant to the issue under investigation and this will be highlighted in the discussion section.

The classrooms for the Experimental group in addition to their being fully renovated, they are equipped with various teaching facilities, i.e., proper arrangement of desks \& seats for students, teacher tables, well painted walls, whiteboards, charts, models, proper lighting \& ventilation, ceiling fans, continuous power supply, and cupboards. In addition to these facilities, the rooms are quite spacious and they are kept clean most of the time.

On the other hand, the classrooms for the Control group have relatively poor environment and lack most of the experimental rooms' facilities. These classrooms mainly have blackboards and benches. The rooms are smaller in size as compared to the rooms of Experimental group. The lighting and ventilation are not quite enough. However, both groups are taught the same material through usual method by experienced English language teachers.

The experiment has started with a placement test given to both groups in the first week of the experimental term with the intention of checking the subjects' initial level of performance in English before experiment. Results of this test indicate no significant difference between the two groups' level of English. In fact, the subjects of both groups have just joined the secondary school after completing an eight-year course of primary education.

The experiment has continued for the whole term during which the students in both groups have studied six units of Spine Four (An English Language syllabus intended for primary and secondary school students in Sudan). After the completion of the syllabus, the researcher has administered an achievement test to examine the level of performance of the both groups to check the effect of the classroom environment on students' performance in English.

The achievement test is constructed and validated by the researcher in collaboration with the English language teachers involved in the experiment. The test aims to measure the students' achievement according to the content and objectives of the first six units of Spine Course taught to the two groups during the experimental period. The test consists of fifty multiple choice items covering the five language skills, i.e., listening, reading, writing, vocabulary, and grammar.

\subsection{Data Analysis}

The students' scores in the achievement test are tabulated and prepared for analyses. The researcher has used Microsoft Office, Excel version 2013, for data entry and analysis. The statistical tests used in this case involve the means as a test of central tendency to compare the scores of the Control and the Experimental group in the achievement test. A t-test is also used to show if the difference between the two groups is significant at $(\alpha=0.05)$.

\section{Findings}

The results of the Control and the Experimental Group students in the achievement test given at the end of the term are tabulated, analyzed and compared. These results are shown in table 1 below: 
Table 1. The Results of the Two Groups in the Achievement Test

\begin{tabular}{ccc}
\hline Skill & Experimental & Control \\
\hline Listing & 66 & 50 \\
Reading & 73 & 53 \\
Vocabulary & 76 & 50 \\
Writing & 60 & 49 \\
Grammar & 50 & 51 \\
Mean & 65 & 50.6 \\
\hline
\end{tabular}

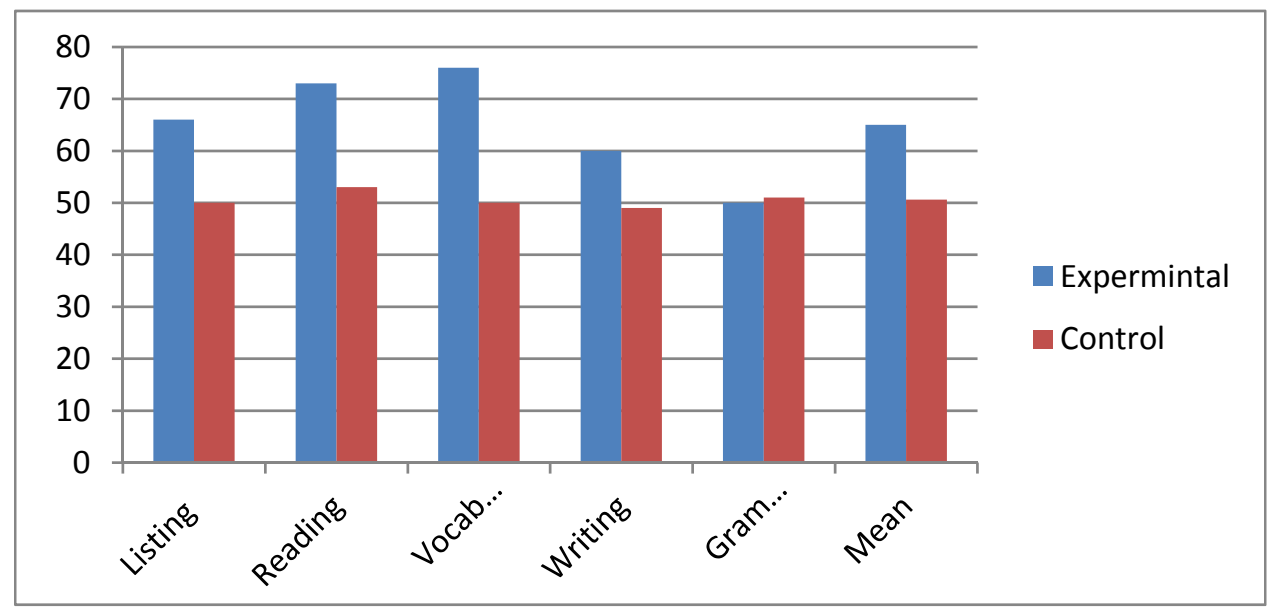

Graph 1. Scores of Exp. and Cont. Group

The above table and graph show the mean, scores of the two groups in the five skills.

It is clear from the above table that the mean scores of the Experimental group students are higher than the mean scores of students in the Control group. The students in the Experimental group score better than their counterparts in the Control group in four of the five language skills. More specifically, it is found that the mean score of the Experimental group in listening is $66 \%$ compared to $50 \%$ for the Control group. In the reading skill, the Experimental group score $73 \%$ compared to $53 \%$ for the Control group. In vocabulary, the Experimental group students score $76 \%$ compared to $50 \%$ by the Control group. The Experimental group students have also done better in writing as they score $60 \%$ compared to only $49 \%$ for the Control group. Surprisingly, the two groups tend to have similar grades in grammar. Indeed, the Control group has done slightly better than their counterpart in the Experimental group. The Control group scores $51 \%$ whereas the Experimental group scores only $50 \%$. However, in the overall score of students in the five skills, the Experimental group has clearly surpassed the Control group. The average score of the Experimental group in all skills is found to be $65 \%$ compared to only $50.6 \%$ for the Control group. Obviously, there is a notable difference between the averages of scores of the two groups in most language skills in favor of the Experimental group, but whether this difference is significant or not, a t- test is done and the result is shown in table 2 below;

Table 2 shows the t-value of the difference between the Exp. And the Cont. group

\begin{tabular}{ccccccccc}
\hline group & $\mathrm{N}$ & $\begin{array}{c}\text { Minimum } \\
\text { mark }\end{array}$ & $\begin{array}{c}\text { Maximum } \\
\text { mark }\end{array}$ & Mean & $\begin{array}{c}\text { Std. } \\
\text { Deviation }\end{array}$ & $\mathrm{t}$ & $\begin{array}{c}\text { Sig. } \\
\text { (2-tailed) }\end{array}$ & result \\
\hline Control Group & 135 & 16 & 75 & 50.6 & 10.829 & 12.6 & 0.000 & Significant \\
Experimental Group & 122 & 45 & 87 & 65. & 9.03 & & & \\
\hline
\end{tabular}


The t- value is found to be 12.6 which indicates that the difference between the two groups' level of performance in English is quite significant at the level of (0.00). This result leads the researcher to conclude that The Experimental group students have done significantly better in English and perhaps in other school subjects because they study in more favorable classroom environments. This result can be cited to answer the main question of the study which inquires about the impact of classroom environment on students' achievement in English. The same result can be quoted to verify the main hypothesis of the study which assumes that provision of adequate Classroom facilities will have a positive influence on the achievement of Sudanese secondary school students in English.

\section{Discussion}

During the research period, the researcher has arranged several observation visits covering the newly renovated schools and those that are not yet renovated. The aim of these observation visits is to check the suitability of classroom atmosphere, adequacy and appropriateness of seating facilities, textbooks availability, libraries, classroom cleanliness, classroom size, and availability of teaching aids and technology. The researcher has come to realize that there are two distinct classroom environments; those in the newly renovated schools and those in non-renovated schools. It is hypnotized that these different classroom environments will reflect directly on students' performance and this is exactly what has happened in to-to. It is revealed that the Experimental group students who study in favourable classrooms environment have done significantly better in the English language test than their counterparts in the Control group who study in less adequate classrooms environments. This finding will be discussed with more details in the following section. In this discussion, the researcher will mainly rely on personal observations backed up with responses generated through interviews with schools administrators and English language teachers involved in teaching the Control and the Experimental group.

Indeed, during the researcher's visits to various schools within the study zone, he finds most of classrooms in non-renovated schools to have small windows and zinc roofs. Surely, there are no air conditioners or even fans to regulate temperature. One of the English language teacher's complains that "After eleven o'clock AM, the classrooms become extremely hot and the temperature rises to above 43 degrees". Unfortunately, most of the English language lessons are normally scheduled after eleven when it becomes extremely hot. Another English language teacher adds," Students in these classes will have problems in acquiring the language skills and the concepts being taught. Their mood is disrupted and they become less motivated and less ready for learning. "One of the schools' administrators admits that "Classroom high temperature influences both students and teachers negatively and reduces their capacity for effective learning and teaching. In fact, this has been the case of the Control group whose performance seems to be negatively influenced by unfavourable classroom conditions.

On the other hand, the researcher is really impressed when he has visited three newly renovated schools. These schools have concrete ceilings instead of zinc, wide windows with glasses, and fans. They are well ventilated and the level of temperature is quite durable even during midday hours. Obviously, this favourable atmosphere reflects positively on students' performance.

Whereas there is a serious attempt by schools administration to provide appropriate and suitable chairs and tables for the students, the non-renovated schools are still using benches and desks. One teacher complains that "The furniture arrangement in the classrooms makes it difficult for us to move around the class to check students' work, as in most cases the furniture occupies the entire classroom limited space." Another teacher says that the seating arrangement doesn't allow students to practice cooperative learning which requires more flexible seating system.

In the renovated schools; however, the researcher has observed that a separate seat and a desk are commonly allocated for each student. One of the administrators has expressed his satisfaction with the seating arrangement saying "The seats are arranged in these classrooms in a way to give space for practicing innovative teaching". Although the administrator does not explain what he means by innovative teaching which is practiced in some of these renovated schools seems to have positive effects on the Experimental group students' achievement in English.

At another level, the researcher has observed that in many schools both renovated and non-renovated, the students, sometimes, share textbooks. One administrator says "Shortage of textbooks have very negative impact on students" performance as it does not allow them to focus on what they are studying". In many cases, the researcher has noticed that teachers write the lesson or part of it on the board for the students to copy, and this consumes a lot of teachers' and students' time. Furthermore, some students cannot find textbooks for revision or preparation of their lessons at home. This issue affects students in both groups' performance negatively. 
Relevant to the above issue of textbooks shortage is the absence of libraries in schools. Libraries are established in schools to maximize student's learning opportunities and help them to utilize their free time properly (Gichuba et al, 2009). Indeed, libraries have many benefits for students. One of the administrators reports that "A library gives students the chance to develop reading habits; libraries help students to integrate a variety of activities around a certain theme, and provide learning opportunities for more than one developmental stage. Students can also borrow textbooks when there is shortage of such books. " But unfortunately, the majority of the renovated and non-renovated schools lack learning libraries. The only exception are two of the newly established schools which have decent libraries, well furnished with bookshelves, references and reading tables. One teacher says "these libraries attract students and provide them with an opportunity to utilize their free time wisely."

It is interesting to note that most of the classrooms visited are fairly clean. Some of them have even dustbins placed inside the classrooms and along the corridors. This has been the case in almost all schools visited except for two that are found quite dirty, littered with papers and dust, which stands as a clear sign that the situation may become worse during certain seasons.

Coming to the issue of classroom size, it is reported that a standard classroom should have a minimum area of 10x8m. This will accommodate a maximum of forty students, says a report by the Ministry of Education in the Sudan. However, in this study the researcher has observed that the majority of the classes in non-renovated schools, in spite of their limited spaces accommodate more than the recommended number of students. This leads to over crowdedness and congestion and results in shortage of fresh air. Ndani (2009) states that air is a survival issue. Lack of adequate supply of fresh air in a classroom means limited supply of oxygen in the body cells. Poorly ventilated and crowded rooms leads to accumulation of the toxic carbon dioxide which often makes students sick, tired and dull. One of the teachers reports that "inadequate classroom size will reflect negatively on learning in general, but more so on language learning." He explains that "language learning activity is affected because there is no space for the students to carry out some important activities essential for language acquisition, such as acting up dialogues or practicing role play.

At another level, it is found that teaching aids are given special attention. In fact, teaching aids help in stimulating students' physical, mental, social, emotional, moral and spiritual developments. Manipulation of audio-visual aids in language teaching activities helps the students to use most of their senses during learning. This makes it easier for them to understand concepts that would have otherwise been difficult to understand (Gichuba et al, 2009). Actually, in this age of technological revolution, computer and other electronic devices have become instrumental in language teaching and learning activities. Language laboratories are now an essential part of modern schools and Computer Assisted Language Learning (CALL) is now rated as the most popular and effective language teaching approach.

Unfortunately, it is widely observed that the majority of the schools lack these essential learning aids and facilities. Those which are in use now are obsolete and out-dated. In fact, Talk and chalk are still dominating the scene making the language learning process dull, frustrating and fruitless.

\section{Conclusion}

The purpose of this study is to investigate the effect of classroom environment on the achievement of first year secondary school students in English. It is an experimental study conducted in Gezira State in Sudan. The sample of the study is formed of two groups; the Experimental and the Control group. The Experimental group students take their English lessons and other subjects in newly renovated classrooms equipped with the necessary facilities that make the learning environment quite favourable. Conversely, the Control group students take their lessons in non-renovated schools under inadequate classroom conditions. Three research questions are formulated to guide the study. These questions sought to establish the effect of instructional resources and classroom environment on the performance of secondary school students in English. Students' level of achievement in English is checked through an achievement test given to both Experimental and Control group at the end of the first term of the academic year 2016-17. The test covers the first six units of the Spine Course which is taught to all Sudanese students in secondary schools.

The results of the achievement test administered to students indicate that the Experimental group students who study in schools with favourable classroom environment have done better in the English test than the Control group students i.e., those who study in schools with unfavourable classroom environment. Students in schools with favourable classroom environments obtained a mean score of $65 \%$ while those of schools with unfavourable conditions have a mean score of $50.6 \%$. A t-test reveals a significant difference in the mean scores between the two 
groups in favour of the Experimental one. From these results, one can easily conclude that classroom environment determines the level of student's performance in English.

Conversely, unfavourable conditions which include small classroom size, inappropriate ventilation, high classroom temperature, shortage of textbooks, and lack of advanced technical teaching aids, coupled with inappropriate desk and seating arrangement seem to have a negative impact on the Control group students' achievement in English. This is very saddening indeed, but one of the school administrators breaks the good news that the Program of Reform and Renovation of schools which started two years ago and reflected positively on the Experimental group students' performance is going to continue to cover all public schools in Gezira state. This renovation process comes as part of the State Governor's plan who intends to implement a radical Reform Project in all parts of Gezira State.

\section{Recommendations}

Initially, this study has proved that classroom environment plays a crucial role in deciding students' academic achievement; therefore, it is recommended that classroom environment should be carefully structured and all necessary facilities should be provided to each school on priority basis.

It necessary then that all classrooms should be fully equipped with instructional aids, supplied with maps, charts, posters and murals etc., as these elements are likely to increase interest, attentiveness and the motivational level of the students.

With respect to classroom size, it is revealed that suitable class size stands as an essential factor that determines students' success in learning different school subjects. This fact makes it important that the government and the Reform Project initiators should enforce the recommended standard size in constructing classrooms throughout the country. This should be particularly stressed when building new schools as part of Gezira State Reform Project initiated by the new State Governor. The government should acquire sufficient funds and land for building schools in suitable locations and stress that the number of students in each class should not exceed the specified limit. Furthermore, classrooms should be designed in such a way that allows various technologies to be used in classrooms. Cupboards and shelves are instrumental and need to be installed in each classroom for keeping various accessories and stationery.

It is also important that proper lighting system should be ensured so that the teaching learning process takes place in a well-lighted, bright atmosphere. In addition, continuous power supply should be ensured and fully secured. To that end, power generators should be installed in each school.

In summer when it really gets very hot, air coolers or at least ceiling fans should be installed to moderate classrooms atmosphere. It is known that unfavorable classroom temperature affects students' mood and performance negatively.

Another important recommendation is connected to textbook availability. Indeed, one of the main problems arising from this research is the low student-textbook ratio. The government is urgently requested to provide enough textbooks to all students and ensures that each student has got his own copy. It is widely documented that there is a positive correlation between students' performance and the level of availability of textbooks.

The last but perhaps the most important recommendation to be made is the provision of audio-visual aids and other teaching devices in classrooms. Audio-visual aids should be made available in all classrooms as these aids play a crucial role in strengthening students' motivation and hence their academic achievement.

\section{Recommendations for Further Study}

In this research, it is clearly demonstrated that classroom environment determines the level of performance of students in English and perhaps in other school subjects. The different elements that form classroom environment require more in-depth and research work. Further research work in this area is needed to determine the effect of classroom environment on other school subjects as this study is mainly focussed on English.

Since the sample of this study is selected from male students only, further research needs to be conducted on female students to check the effect of classroom environment on their achievement in English. It is well known, in this part of the world that female students respond differently to different classroom environmental stimuli.

There is also a need to carry out further research on the importance of libraries, stationaries and playgrounds inside school buildings. Finally, further research work should be carried out to establish the effect of non-physical elements in classroom environment on students' academic achievement. So far, it is not yet clear how issues like classroom 
disciplines, use of particular teaching methods and provision of feedback influence students' performance in the target subject.

\section{References}

Ashton, C. (2001). Life Skills Project Implementation in the AmericanEducation System. YAREVAN: UNICEF.

Atkinson, G. B. J. (1987). The Economics of Education. London.

Avalos, M. (1991). The status of Latinos in the profession: Problems in Recruitment and retention. Political Science and Politics, 24(2), 241-246. https://doi.org/10.2307/419943

Bascia, B. (2003). Achieving Universal Primary Education by 2015. A chance for every child Washington DC: World Bank

Best, J. W., \& Kahn, J.V. (2001). Research in Education (7th ed.). New Delhi: Prentice-Hall of India.

Chuma, P. C. (2012). Challenges Affecting Teaching-Learning in Primary Schools in Kenya.

Collin, E., \& Rosmiller, R. A. (1987). Research on effective schools Implications for less developed countries, Comparative Education Review

Dihaisat, F. (2016). Impact of Classroom Environment on Jordanian Secondary School Students. Unpublished MA Thesis, Islamic University.

Fuller, B. (1986). Raising School Quality in Developing Countries: What Investments Boost Learning? Washington D.C: World Bank.

Gichuba, C. et al (2009). General methods of teaching young children and material development. Nairobi: Sasa Sema Publishers.

Gichara, M.W. (2010). Effects of instructional materials on participation in class activities

Hassan, D. (2016). Technology in Language Teaching. M.A Thesis. University of Gezira.

Heyneman, S., \& Loxley, W. A. (1981) Textbooks and Achievement in Developing Countries. Journal of curriculum studies, 13, 146-227

Hines, E. (1996). Building Condition and Student Achievement and Behaviour. Unpublished doctoral dissertation Blacksburg, V A: Virginia Polytechnic Institute and State University.

Kilei, J. K. (2012). Factors Influencing Quality Training in Public Primary TTC in Rift Valley Zone, Kenya. Executive Med project, Moi University

Ministry of Education. (2003). Report on Sector Review and Development in Sudan: Government printers.

Ndani, M. (2009). Child Rights and Child Protection. Nairobi: Longhorn Publishers.

Nwangwu, N.A. (1990). Universal primary education: Issues, problems and prospects. Benin City: Ethiop Publishers.

Punch, K. F (2004). Introduction to research methods in educationalist. Angeles: Sage Publications ltd

Salem, R. (2005). Impact of Classroom Atmosphere on Students'Achievement. Unpublished MA Thesis: University of Sudan for Science and Technology

Tayib, A. (2016). Improving Reading Comprehension by using Graphic Organizers. Unpublished MA. Thesis: Gezira University.

Tsavga, J. (2011). The effect of environment on the academic performance of students in Tarka Local Government Area of Benue State.

Umar, A. (2015). Use of Mind maps in Teaching Reading for ESP Students: A Case Study of the Preparatory Students at UQU.

Williams, J., Turner, P., \& Persaud, D. (2008) School Plant Planning as Correlate of Students' Academic Performance in Secondary Schools. International Journal of Business Administration, 12(2). 